\title{
WHAT CONSTITUTES GOOD VULCANIZING?
}

\author{
By Dr. George B. Snow, Long Beach, Cal.
}

(Read before National Society of Denture Prosthetists, 1919, New Orleans, La.)

$\mathrm{D}$ URING all the years that vulcanite has been used as a base for artificial dentures there has been but little change in the methods employed by dentists for vulcanizing. Many improvements have been made in vulcanizing apparatus, one of which, the Mercury Bath Thermometer, has proved a stumbling block to dentists; altho it is one of the greatest improvements that has been made, so far as vulcanizing apparatus is concerned. It was many years before it was noticed that the Mercury Bath, by reason of its deterrent effect upon the transmission of heat to the thermometer tube, allowed the vulcanizer to be actually some $18^{\circ}$ or more hotter than the thermometer registered. The effect of included air upon the thermometer was not noticed for many years. These facts are now better understood and, as a consequence, the mishaps attendant upon vulcanizing are not nearly so frequent as they once were, but they still occur. Teeth are insecurely held in the vulcanite, and there are unsightly gaps apparent at times which detract from the appearance of the work and render it unsanitary.

It came to the writer, about forty years ago, when he was investigating some of the phenomena attendant upon vulcanization, that the conversion of the compound of Caoutchouc and Sulphur into vulcanite was attended by a notable amount of shrinkage; and it was at once perceived that this fact was the cause of some of the difficulties encountered by dentists in their prosthetic work. Upon further experimenting it was found that the amount of shrinkage was diminished by the addition of extraneous substances, such as the vermilion, used as coloring matter. The black vulcanite, which contained but little more than Caoutchouc and Sulphur, was notoriously much more troublesome to use successfully than was the red vulcanite, which contained a very considerable proportion of vermilion in its composition; this difference between the working qualities of red and black vulcanite being well known to dentists as a fact. The shrinkage attendant upon vulcanization, however, when brought to notice as accounting for this difference, received but scant attention. The application of spring pressure upon the flask for closing it was urged as a convenient means for obviating the annoyances attendant upon the shrinkage during vulcanization, and various appliances for producing spring pressure have been devised and used; but to this day, probably not many more than onethird of the Dental Schools in the United States use anything but the old fashioned rigidly bolted flask in their teaching, and when they do this in the laboratories, it is a fair presumption that the shrinkage attendant upon the conversion of rubber compound into vulcanite receives scant mention, if any, in their didactic instruction; and now 
at the expiration of forty years, the matter has but lately received any attention in the text books.

In order to answer the question propounded as a title to this paper it may be well to follow the process of vulcanization thru, from flasking the case to the removal of the vulcanite denture from the flask. There are many of the minutiae which are too well known to require mentioning, but each is nevertheless important in its way. Of these, the first is the plaster which is to be used. This must be capable of setting so as to form as hard and as resistant a mass as possible; and this depends very much upon the manner in which it is mixed. The less water used, the better, if the plaster can be properly worked. If water is added in sufficient quantity so that the plaster flows readily, the resulting mix will not be as hard, after it has set, as it would be if it is stiff enough so that it requires some jarring to make it flow. This is particularly true when pouring the cast or model, for this must sustain any pressure which may be brought upon it. If it yields ever so slightly, the result is likely to be an impairment of the fit.

The flask used should be well fitted, the sections should not rock upon each other when placed together, and the guide pins should fit their notches accurately and perfectly; so that while the sections of the flask will separate easily, there shall not be the slightest lateral movement when they come together.

After the plate is flasked and the flask is separated, the removal of the trial plate from the mold is a matter of routine; but it is well to save every particle of it and mold it into a compact mass in order to be able to ascertain the exact amount of rubber compound necessary for the case. This is done by the Immersion Process, which is well known.

\section{Cutting the Gateways.}

Illustration No. 1, a familiar one in the text books, shows the manner which is usually advised for performing this operation. It is by no means the best method, for it affords too little room for surplus, and leaves too much of the face of the plaster which comes into contact with that of the other section of the flask, when the flask is closed. There are plenty of notches thru which the rubber may escape from the mold,

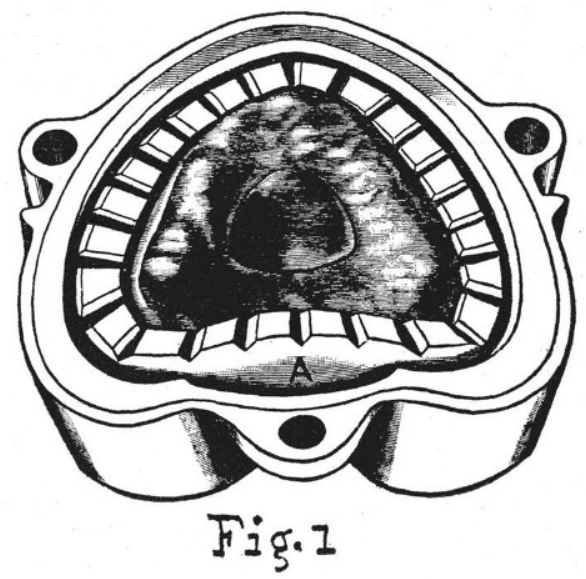

and too little room to receive it after it has escaped. Some of this rubber, if there is any quantity of it, will certainly be caught between the opposing surfaces of the plaster, and while it may be pressed into a fairly thin sheet, it cannot be completely expelled by any pressure which may be brought upon the flask to close it, and the result may be defective articulation of the teeth. If the flask is to be closed by rigid bolts, the notches leading from the mold for the escape of the rubber are necessary, but the result is a deficiency in vulcanite in the denture.

The method shown in Figure 2 is much preferable. Here, all the surface of the plaster is removed so that there is a large overflow chamber completely 
encircling the mold, with only a narrow margin remaining of the original surface of the plaster. This is left without the escape notches, and the expansion of the rubber with which the mold is packed will separate the two sections of the flask, if it is closed under spring pressure. The rubber will then escape thru the interval between the two sections into the overflow passage. Then as the rubber shrinks in vulcanizing the sections of the flask will again come together, and there being but a narrow margin of plaster remaining immediately around the mold, the bearing of the springs is thrown upon this margin, and the rubber either yields to the pressure of the edge, or possibly the plaster yields to the pressure of the rubber. In any event the flask is closed much more perfectly than it would be closed by the method shown in Figure 1.

The amount of shrinkage varies in different samples of Dental Gums, as it depends upon the amount of extraneous matter which has been added, either as pigment or "filler", the latter being added by the manufacturer to control and diminish the shrinkage. In the case of the rubbers ordinarily used, it will vary from three to five per cent. A certain amount of the rubber is expelled from the mold into the overflow chamber when it is heated to the vulcanizing point, and the amount of this, again, varies according to the construction of the rubber, the percentages running from four and one-half to five and one-half per cent. The total deficiency then in the mold chamber, when the rubber is vulcanized in the ordinary way in the rigidly bolted flask, will vary from about seven and $6 / 10$ to over ten per cent. Under these circumstances, it is not at all strange that there should be defects in the dentures so vulcanized. It is more remarkable that defects appear so seldom.

When a piece of rubber compound is vulcanized, the result is always a considerable reduction in the volume of the mass, and in order to secire results, which are free from defects, it is absolutely necessary that we begin the vulcanizing process with more rubber than the mold will contain when closed. The rubber must be molded into its proper shape while it is soft, and as it is vulcanized, the mold must be closed upon it to follow up its shrinkage in a way somewhat analogous to the molding

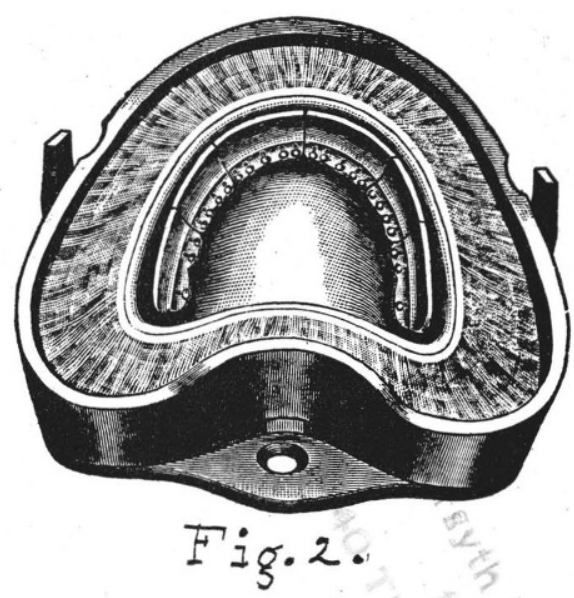

of a celluloid blank. The amount of surplus rubber in the mold should be at least five per cent, and it can be best controlled by using sheet metal props to prevent the complete closure of the flask; the amount of surplus rubber retained depending upon the thickness of the props used.

To determine the time at which shrinkage occurs, samples of rubber compound have been vulcanized at various times, from five minutes to the usual time for vulcanizing, and it has been ascertained that the shrinkage takes place more rapidly during the first half of the time for vulcanizing; there being but little change during the latter half; and in order to compensate for the shrinkage when an ordinary vulcanizer 
is used, it will be necessary to vulcanize twice, once for about half the usual time for vulcanizing, with the sections of the flask held apart by the props, and again for the other half of the time with the props removed and spring pressure applied to close the flask and thus compensate for the shrinkage.

If a vulcanizer is used having a flask closing attachment, by means of which the flask can be closed at the pleasure of the operator and while the vulcanizing process is going on, a single vulcanization will suffice; the flask being gradually closed as vulcanizing proceeds.

\section{The Vulcanizing Temperature.}

When Dental Gum was first furnished to the profession, the directions for vulcanizing it called for $320^{\circ}$ temperature, Fahr. for about two hours time. The use of the Mercury Bath Thermometer, and improved methods of constructing vulcanizers by which they could be made to remain steam tight, resulted in an unnoticed, but a considerable elevation of the vulcanizing temperature, the result being that the time of vulcanizing was diminished from two hours to one hour or even less.

The transmission of heat was impeded in two ways. A certain amount of air is always included in the vulcanizer when it is closed, and the mixture of air and steam, which results when the vulcanizer is heated, does not transmit heat as readily as does an atmosphere of pure steam; the result being a lowering of the indication of the thermometer of about $20^{\circ}$, and of the apparent temperature; while the real temperature is increased. This difficulty is overcome by opening the blow-off valve and permitting the escape of a certain amount of steam, which carries off the air with it.

The mercury bath itself, being a part of the cover of the vulcanizer, is only as hot as the exterior of the vulcanizer. Considerable heat is lost in its trans- mission thru the metal of the vulcanizer by radiation from the exposed surface, and by contact of the cold air, the result being another lowering of the indication of the thermometer. The transmission of heat thru the mercury bath is always imperfect and the indication of the thermometer from this cause alone is delayed $18^{\circ} \mathrm{Fahr}$. or more; the flask and its contents being accordingly exposed to a considerably higher temperature than was contemplated in the directions for vulcanizing as originally given. While thin pieces of rubber may be vulcanized at $320^{\circ}$ as shown by the mercury bath thermometer, it is questionable if the work is as well done as it would be at $320^{\circ}$ actual temperature, as specified in the original directions. If the piece of rubber to be vulcanized is thick, say a quarter of an inch or more, it is very apt to come out spongy or porous, and it is recommended that the vulcanizing temperature should not exceed $300^{\circ}$ by the mercury bath thermometer; $320^{\circ}$ actual temperature; the time being increased to two hours, or thereabouts, from the time when the vulcanizing temperature is reached. For still thicker pieces the time should be increased and the temperature still further reduced. The product will then have more toughness, and if successive vulcanizations are necessary, more of them will be endured before the vulcanite will become so brittle as to need replacement.

When vulcanite is once well hardened it remains of very nearly the same density thereafter, and shrinks but very little if repeatedly vulcanized.

\section{EXPANSION AND CONTRACTION OF Vulcanite.}

Vulcanite expands by heat and contracts by cooling more than any other solid substance, and this fact must be remembered; as irregular cooling of a vulcanite denture will be very apt to 
produce warpage and result in a misfit. If it is slowly and regularly cooled it is held by its attachment to the plaster investment while cooling so that the plate retains its size and shape; as the vulcanite remains soft and cartilaginous until it has reached a temperature of about $130^{\circ} \mathrm{Fahr}$. It then stiffens as the temperature lowers, but it has nearly reached the ordinary temperature of the room and its contraction during this small range of temperature cannot be avoided, and is not sufficient to call for notice. Better results will be attained if the flask and its contents are allowed to cool slowly; and it is also a question if it is not better to allow them to remain undisturbed for an hour or so after they reach the temperature of the room, for it is probable that a certain molecular change takes place in the vulcanite which is not completed until after a short time beyond the period of its cooling.

The adhesion of the vulcanite to the plaster investment has been mentioned above. This controls the manifestation of its shrinkage, as when this takes place the vulcanite separates from the smoother and more dense surfaces of the teeth and tooth-pins. As a consequence the tooth-pins are not firmly held in the vulcanite, nor are the teeth as well supported by it as they might be. This is the cause why the incisor teeth often loosen and start forwards, and why gaps appear between the teeth and vulcanite.

The contraction of the vulcanite in cooling is a factor to be reckoned with in another way. The denture should be kept under mechanical pressure after vulcanizing is completed and until it is thoroly cooled; and it is impossible to do this unless sufficient extra rubber is used to fully compensate for the shrinkage; and also to compensate for the contraction in cooling.

Good vulcanizing is a process which requires considerable care and judgment. The working qualities of different brands of dental gum vary considerably, and in their use the thickness of the denture to be produced must be taken into account, not only in order to ascertain the quantity of gum required to fill the mold, but also to enable the dentist to modify the temperature of vulcanizing if very much rubber is required. When the work is done in a hap-hazard way and without due consideration of all the circumstances, mishaps will occasionally occur and need not be wondered at. The only wonder is that they do not occur more frequently. 